\title{
Atypical presentation of metastasized renal cell carcinoma
}

\author{
Diogo Fábio Dias Teixeira ${ }^{*}$ \\ Juliana Cristina Duarte Braga' \\ Joyce Kelle Gomes Barbosa Ribeiro² \\ Igor Caldas Santos ${ }^{2}$ \\ Marcos Duarte Guimarães ${ }^{3}$
}

\begin{abstract}
1. Graduating in Medicine from the University Anhembi Morumbi, São Paulo, SP, Brasil 2. Resident doctor of Heliópolis Hospital, São Paulo, SP, Brasil 3. MD. Ph.D. Professor of Radiology of the Federal University of the Sao Francisco's Valley and Coordinator of the Residency Program of Radiology at the Heliópolis Hospital, São Paulo, SP, Brasil
\end{abstract}

http://dx.doi.org/10.1590/1806-9282.64.11.983

KEYWORDS: Carcinoma, renal cell. Neoplasm metastasis. Delayed diagnosis. Tomography, X-ray computed. Histology. Perivascular epithelioid cell neoplasms.

\section{INTRODUCTION}

Renal cell carcinoma (RCC) is a heterogeneous family of neoplasias. Currently it corresponds to 90\% of all renal malignancies and is the most lethal of urological tumors. ${ }^{1}$ Now, with the increased frequency of imaging exams in the general population, many of these tumors are detected coincidentally; two-thirds of them occur in men..$^{1,2}$

Clinical manifestations of RCC include hematuria $(60 \%)$, back pain $(40 \%)$, and palpable flank mass (30-40\%). ${ }^{1,2}$ The most common histological types are clear cell, papillary, and chromophobe carcinomas. About $25-59 \%$ of patients with RCC present with distant metastasis at the time of diagnosis. ${ }^{3}$

Clear cell carcinoma is the most common histological subtype of RCC, representing 70-75\% of cases. ${ }^{1,2}$ It occurs typically around the age of 50 years. The most frequent locations are the lungs (50\%), bones (33\%), lymph nodes $(15 \%)$, skin $(11 \%)$, liver $(8 \%)$, and brain
(3\%). ${ }^{1}$ Adrenal gland metastases are rare, occurring in less than $10 \%$ of patients, and they are generally silent. Imaging techniques such as ultrasound (US), computed tomography (CT), and magnetic resonance imaging (MRI) play an important diagnostic role in RCC; they enable early detection and are essential for therapeutic staging and planning. Chest x-ray and urine cytology are also used in the diagnosis of this disease. Complete surgical resection continues to be the only curative treatment for RCC.

\section{CASE}

A male patient aged 59 years and residing in São Paulo, Brazil, with systemic arterial hypertension and type 2 diabetes, and no previous history of surgery was admitted to the emergency room with a history of vertigo and two episodes of fainting in the two pre- 

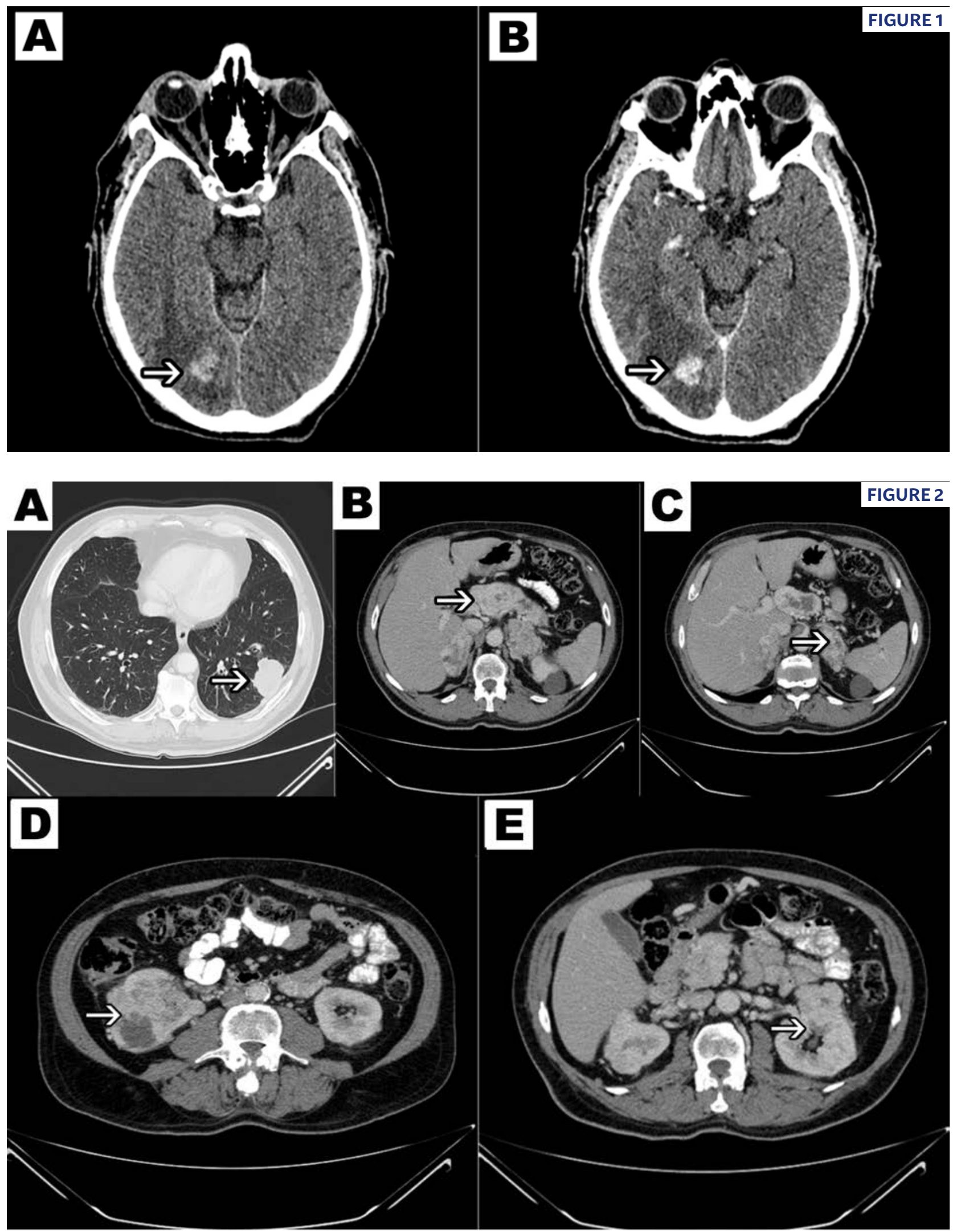

vious months. The findings of physical, neurological, and laboratory tests were not remarkable. Due to limited clinical open neurological status, we started a CT scan of the skull and found a series of brain metasta- ses (Figure 1). As a result of the presence of encephalic nodules with the appearance of metastases, a search was made for the most frequent tumors in the male sex: lung, colorectal, and prostate. However, physical 


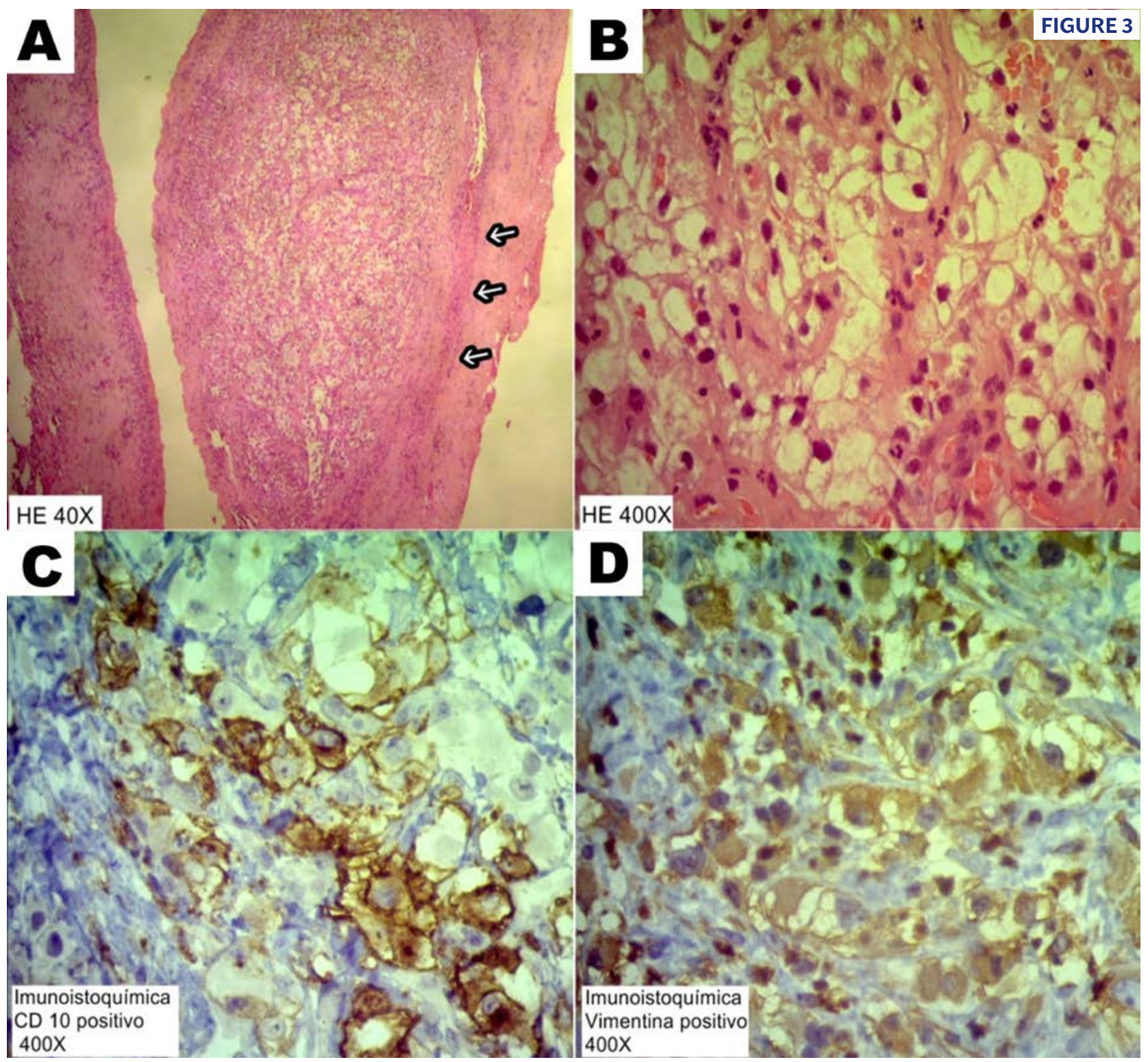

examination revealed no abnormalities, thus restricting the diagnosis for some subtypes of tumors such as lung, melanoma, kidney, and gastrointestinal neuroendocrine tumors. CT of the thorax, abdomen and pelvis revealed a sizeable continuous mass of $5.9 \times 5.5$ $\times 5.4 \mathrm{~cm}$ and solid pulmonary nodules (Figure $2 \mathrm{~A}$ ), as well as hypervascular masses in the pancreas $(6.2 \times$ $5.9 \times 4.6 \mathrm{~cm}$ ) (Figure 2B), kidneys and bilateral adrenal glands $(7.4 \times 6.8 \times 6.4 \mathrm{~cm})$ (Figure $2 \mathrm{C}$ ). Based on the hypervascular appearance of multiple lesions, a primary tumor of the kidney was suspected. This diagnosis was confirmed by a biopsy of one of the abdominal masses that proved to be a clear cell tumor of the kidney. The patient started treatment with systemic chemotherapy and developed febrile neutropenia. As a result of this latter condition, chemotherapy was discontinued at the end of the first cycle. Thirty days later, because of septic shock, he died of multiple organ failure.

\section{DISCUSSION}

This report, duly consented to by the study patient, demonstrates a case of multiple hematogenic metastases of renal clear cell carcinoma to various organs including the pancreas, adrenal glands, and kidney (Figure 2D, 2E). Clear cell carcinoma represents $80 \%$ of metastatic cases, and metastasis sites are often multiple ${ }^{2}$ (Figure 3).

Lung metastases are responsible for $14 \%$ of all metastatic RCCs, thus representing the most common anatomical site of dissemination. They are asymptomatic in $90 \%$ of cases. The lesions are usually well circumscribed, rounded, and subpleural. Pancreatic metastases originating from any tumor are exceptionally rare. Pancreatic involvement in RCC metastasis accounts for only $0.25 \%$ to $3 \%$ of cases. ${ }^{4}$ The diagnostic sensitivity 
of US and CT for renal cell carcinoma is $79 \%$ and $94 \%{ }^{1}$

CT and MRI are essential in the monitoring of these patients. Imaging tests are crucial for the early diagnosis of metastasis. ${ }^{5}$ The histological diagnosis of carcinomas is also of critical importance, as the histological subtype has significant prognostic and therapeutic implications.

\section{CONCLUSION}

Radiologists must be familiar with atypical presentations of metastatic renal tumors and include a differential diagnosis for renal cell carcinoma when imaging examinations reveal multiple chest and abdominal hypervascular lesions.

Conflict of interest: None.
Palauras-chave: Carcinoma de células renais. Metástase neoplásica. Diagnóstico tardio. Tomografia computadorizada por raios $X$. Histologia. Neoplasias de células epitelioides perivasculares.

\section{REFERENCES}

1. Young |R, Margolis D, Sauk S, Pantuck A|, Sayre J, Raman SS. Clear cell renal cell carcinoma: discrimination from other renal cell carcinoma subtypes and oncocytoma at multiphasic multidetector CT. Radiology. 2013;267(2):444-53.

2. Hugo HS. Cancer. In: McPhee SI, Papadakis MA, eds. Current medical diagnosis and treatment. 48 ${ }^{\text {th }}$ ed. New York: McGraw-Hill LANGE; 2009. p.1463-4; 1489-90.

3. Ljunberg B, Campbell SC, Choi HY, Jacqmin D, Lee JE, Weikert S, et al. The epidemiology of renal cell carcinoma. Eur Urol. 2011;60(4):615-21.

4. Ko S, Yun S, Kim S, Kim TN, Seo HI. Pancreatic resection for renal cell carcinoma metastasis: a case review. Ann Hepatobiliary Pancreat Surg. 2017;21(3):176-9.

5. Lee-Felker SA, Felker ER, Tan N, Margolis D|, Young |R, Sayre |, et al. Qualitative and quantitative MDCT features for differentiating clear cell renal cell carcinoma from other solid renal cortical masses. AJR Am | Roentgenol. 2014;203(5):W516-24. 